Recebido em 11/2018. Aceito para publicação em 03/2019.

\title{
MOBILIDADE HUMANA: POLÍTICAS LINGUíSTICAS E PROMOÇÃO DA IGUALDADE ENTRE OS PAÍSES
}

\section{MOVILIDAD HUMANA: POLÍTICAS LINGÜÍSTICAS Y PROMOCIÓN DE LA IGUALDAD ENTRE LOS PAÍSES}

\section{Luana Ferreira Rodrigues ${ }^{1}$}

Resumo: O presente artigo tem como objetivo discutir a importância da formulação de políticas públicas que visem a promoção da igualdade entre os países, tendo como base os Objetivos para o Desenvolvimento Sustentável da Organização das Nações Unidas, no que concerne à mobilidade humana e integração dos cidadãos migrantes. Desta forma, defende-se no texto o conceito das fronteiras livres por meio de teóricos que tratam sobre o tema, trazendo breves considerações sobre a Lei $n^{\circ}$ 13.445/2017, chamada de Lei de Migração, e chegando à importância da Política Linguística nesse processo, por meio do planejamento e elaboração de ações que possam gerir a questão das línguas dos migrantes, pensando no plurilinguísmo, e seu acesso à língua portuguesa como um dos direitos desse cidadão.

Palavras-chave: Mobilidade humana; políticas linguísticas; fronteiras livres; promoção da igualdade.

Resumen: El presente artículo tiene como objetivo discutir la importancia de la formulación de políticas que busquen la promoción de la igualdad entre los países, según preconizan los Objetivos para el Desarrollo Sostenible de la Organización de las Naciones Unidas, en lo que se refiere a la movilidad humana e integración de los ciudadanos migrantes. De esta manera, se defiende en el texto el concepto de las fronteras libres a través de teóricos que discuten el tema, proponiendo un breve análisis acerca de la Ley n¹3445/2017, conocida como "Ley de Migración", llegando a la importancia de la Política Lingüística en este proceso, desde su planificación y elaboración de políticas que puedan gestionar la cuestión de las lenguas de los migrantes, pensando en el plurilingüísmo, y su acceso a la lengua portuguesa como uno de los derechos de este ciudadano.

Palabras-clave: Movilidad humana; políticas lingüísticas; fronteras libres; promoción de la igualdad.

\section{INTRODUÇÃO}

A mobilidade humana é uma constante no processo de construção sócio histórica do Brasil, desde a chegada dos colonizadores, à mobilidade forçada e violenta do período escravocrata, à imigração europeia do início do século $\mathrm{XX}$, e nos dias atuais, à acolhida de refugiados haitianos e a recente onda de imigração oriunda de países vizinhos, como a Venezuela.

São várias as razões que levam pessoas a migrarem de seus países, entre elas estão a busca por melhores postos de trabalho, melhores condições de vida para a família, aperfeiçoamento acadêmico, perseguições, violência, conflitos, desastres ambientais e a pobreza extrema. Esses fluxos de migrantes e refugiados, geralmente, ocorrem de países menos desenvolvidos ou em desenvolvimento para países desenvolvidos, mas também se observa que a falta de recursos econômicos para o deslocamento tem permitido fluxos migratórios entre países vizinhos, como é o caso

\footnotetext{
1 Doutoranda em Linguística pela Universidade Federal de Santa Catarina, Docente na Universidade Federal do Amazonas, Brasil. E-mail: Iferdrigues@gmail.com.
} 
do fluxo venezuelano rumo a países como Brasil e Colômbia.

O tema da migração passou a ser uma preocupação sociológica no início do século $\mathrm{XX}$, cujos estudos classificavam o processo como consequência do avanço do capitalismo, ligada aos processos de industrialização, mobilidade de pessoas das áreas rurais para as áreas urbanas e crescimento da urbanização.

Richmond (1988, p. 7), ao tratar sobre as teorias da migração, divide-as em macro e micro teorias enquanto nível de análise. A macro teoria se concentra nos fluxos migratórios, nas condições e caracterização desses imigrantes no país de origem, abordando também o seu processo de adaptação no país escolhido. A micro teoria, por sua vez, se dedica a questões mais individuais dos migrantes, desde uma perspectiva sociopsicológica, diferenciando migrantes de não-migrantes e sem levar em consideração questões sociais mais amplas. Em outras palavras, as teorias macro e micro, propostas pelo mesmo autor, levam em consideração desde as questões mais amplas que envolvem os grupos de migrantes dos grandes fluxos populacionais, como as condições econômicas, sociais, demográficas e políticas no país de origem (macro) a questões de identificação individual dos migrantes e os novos desafios enfrentados no que se refere à adaptação no novo país (micro).

A perspectiva teórica deste trabalho leva em consideração a migração enquanto um fenômeno transnacional, em que predomina a manutenção de laços culturais, sociais e emocionais com o país de origem, desconsiderando a ideia de assimilação e aculturação proposta por teorias anteriores vinculadas à Escola de Chicago. Com o advento da tecnologia e das redes sociais, essas fronteiras se tornam cada vez menos existentes, uma vez que a distância geográfica não impede o acesso em tempo real a notícias e o contato com familiares, as transações comerciais e financeiras que podem ser realizadas pelo imigrante no país receptor, muitas vezes, utilizando sua própria língua, ou através de tradutores online. De acordo com dados disponibilizados pelo Departamento de Assuntos Econômicos e Sociais das Nações Unidas (UN DESA)2, no ano de 2015, o número de migrantes internacionais atingiu um total de 244 milhões, um percentual $41 \%$ maior do que o registrado no ano 2000 , enquanto o número de refugiados passou de 16 milhões, em 2000, para 20 milhões, em 2015.

No Brasil, esse número também aumentou, de acordo com levantamentos feitos pela Polícia Federal e pelo Ministério da Justiça através da solicitação de autorizações para residência e trabalho no país e entradas em solicitação de permanência como refugiados. A recente crise na Venezuela contribuiu com esse aumento, uma vez que todos os dias chegam a pé, pelas fronteiras no Norte do país centenas de pessoas fugindo da crise econômica que assola o país vizinho, solicitando a entrada no Brasil na condição de refugiados.

\footnotetext{
2 Dados e gráficos disponíveis para acesso em:

http://www.un.org/en/development/desa/population/migration/data/estimates2/estimatesgraphs.shtml?0g0 Acesso em 30 jan. 2019.
} 
Diante do contexto atual aqui descrito, este artigo tem como objetivo discutir a importância da modernização da legislação voltada para a mobilidade humana e da abertura das fronteiras em sua relação com os Objetivos para o Desenvolvimento Sustentável propostos pela Organização das Nações Unidas (ONU, 2015) em especial com o objetivo 10 que propõe "reduzir a desigualdade nos países e entre eles", focando em três de suas metas:

10.2 Até 2030, empoderar e promover a inclusão social, econômica e política de todos, independentemente da idade, gênero, deficiência, raça, etnia, origem, religião, condição econômica ou outra.

10.3 Garantir a igualdade de oportunidades e reduzir as desigualdades de resultados, inclusive por meio da eliminação de leis, políticas e práticas discriminatórias e da promoção de legislação, políticas e ações adequadas a este respeito.

10.7 Facilitar a migração e a mobilidade ordenada, segura, regular e responsável das pessoas, inclusive por meio da implementação de políticas de migração planejadas e bem geridas. ${ }^{3}$

Pensando no grande contingente de fluxo migratório atual no Brasil e em outros países e nos objetivos para o desenvolvimento sustentável anteriormente mencionado, este artigo busca também trazer algumas reflexões sobre as políticas migratórias brasileiras a partir da análise da Lei 13.445/2017 (BRASIL, 2017a). Além disso, apresenta uma breve discussão sobre a importância do conceito de estados transnacionais, baseada nos estudos do sociólogo alemão Ulrich Beck, para o tema da mobilidade humana e o exemplo do Equador com sua visão de cidadania universal e abertura das fronteiras como forma de integrar cidadãos em situação migratória no país.

\section{POLÍTICAS MIGRATÓRIAS BRASILEIRAS}

A legislação brasileira que regulamentava a questão da imigração era da década de oitenta, anos finais da ditadura militar, e se tornou desatualizada diante das transformações sociais e políticas do país ocorridas nas últimas décadas.

A chamada "Lei do estrangeiro", a Lei n 6815/1980 (BRASIL, 1980), definia a situação jurídica do estrangeiro no Brasil e criava o Conselho Nacional de Imigração (CNIg). O CNIg foi responsável por tentar modernizar essa lei por meio de portarias e resoluções que buscavam solucionar questões não previstas na legislação vigente, entre elas a Normativa 80/2008 que regulava a concessão de autorização de trabalho para obtenção de visto temporário a estrangeiro com vínculo empregatício no Brasil dando especial atenção a trabalhadores de origem sul-americana.

\footnotetext{
3 Disponível em:

$<$ http://ec.europa.eu/eurostat/statisticsexplained/index.php/Migration_and_migrant_population_statistics/pt>.
} 
Como mencionado anteriormente, o Brasil tem recebido nos últimos anos um número expressivo de imigrantes e refugiados, em especial da Venezuela, dadas as condições políticas e socioeconômicas desse país, e com essa nova configuração percebe-se o despreparo e ausência de legislação e planejamento voltados para o acolhimento de imigrantes em nosso país.

$\mathrm{Na}$ tentativa de se criar uma lei que apoiasse os imigrantes que chegavam ao país, em 2015 surgiu um projeto de lei (PL 2516/2015) que originou a atual Lei de Migração, Lei $\mathrm{n}^{\circ}$ 13.445/17 (BRASIL, 2017a). O projeto de lei foi aprovado com diversos vetos incluindo um que se refere ao conceito de migrante:

\section{Inciso I do $\$ 1^{\circ}$ do art. $1^{\circ}$}

I - migrante: pessoa que se desloca de país ou região geográfica ao território de outro país ou região geográfica, incluindo o imigrante, o emigrante, o residente fronteiriço e o apátrida;

\section{Razões do veto}

"O dispositivo estabelece conceito demasiadamente amplo de migrante, abrangendo inclusive o estrangeiro com residência em país fronteiriço, o que estende a todo e qualquer estrangeiro, qualquer que seja sua condição migratória, a igualdade com os nacionais, violando a Constituição em seu artigo 5o, que estabelece que aquela igualdade é limitada e tem como critério para sua efetividade a residência do estrangeiro no território nacional." (BRASIL, 2017a)

Em sua defesa do veto, o governo federal deixa claro seu incômodo em relação ao residente fronteiriço, o qual não pode ser considerado um migrante. Desta forma, o conceito de migrante foi retirado da Lei, mantendo-se apenas o termo imigrante:

II - imigrante: pessoa nacional de outro país ou apátrida que trabalha ou reside e se estabelece temporária ou definitivamente no Brasil; (BRASIL, 2017a)

Desta forma, pode-se questionar: Como um país que revoga uma lei que pretende estender aos estudantes brasileiros o contato com a língua espanhola, língua falada pelos denominados pela mídia como "invasores venezuelanos", pode promover uma integração entre migrantes e brasileiros?

Em sua Constituição, o Brasil se propõe a estabelecer uma rede de integração com os países vizinhos, como deixa claro no Art. 4: "A República Federativa do Brasil buscará a integração econômica, política, social e cultural dos povos da América Latina, visando à formação de uma comunidade latino-americana de nações" (BRASIL, 1988).

A antropóloga Bela Feldman-Bianco (2015) afirma que o Brasil ainda precisa avançar no sentido de promover políticas migratórias que visem à proteção dos direitos humanos diante do atual contexto migratório do país, que difere daquele do 
século XIX, cujo objetivo era o branqueamento do país com a chegada de imigrantes considerados "desejáveis" (grifo da autora) pelo Estado:

O Brasil e suas políticas desenvolvimentistas, assim como outros países sul-americanos, passaram a atrair novos imigrantes. [...] No entanto, esses recém chegados se confrontam com a falta de políticas, de estrutura e de assistência social. Nesse contexto, o caso dos haitianos que estão sendo enviados pelo governo do Acre para São Paulo é emblemático. Apesar de ser a primeira cidade do Brasil a contar com uma coordenação de políticas para migrantes, a prefeitura de São Paulo ainda não tem estrutura para receber imigrantes (FELDMAN-BIANCO, 2015).

Não obstante, observa-se que apesar de ser signatário de acordos e estatutos e ter sancionado a Lei de Refúgio (Lei n 9474/97), ainda se faz necessário o planejamento e a implementação de políticas que permitam um tratamento mais adequado das questões de mobilidade humana respeitando os direitos dos cidadãos migrantes (BRASIL, 1997).

\section{ESPAÇOS SOCIAIS TRASNACIONAIS, FRONTEIRAS LIVRES E POLÍTICAS LINGUÍSTICAS}

A migração é um fenômeno que se dá por motivos diversos, mas na grande maioria dos casos, o que leva as pessoas a saírem de seu país natal é a busca por melhores condições de vida.

Sobre o processo migratório, o sociólogo alemão Ulrich Beck (2008, p. 69) em seu livro "O que é a globalização? Falácias do globalismo, respostas à globalização", afirma que:

no mundo ideológico e político das sociedades individuais organizadas segundo o modelo nacional-estatal, a migração se divide nas fases e contextos (que também devem ser estudados casualmente separados) da partida, a viagem, a chegada e a integração (que também pode fracassar).

Seguindo as ideias de Beck (2008), cabe aqui problematizar a necessidade de uma tomada de consciência sobre a urgência de uma reconfiguração dos Estados não como nacionais-estatais, mas como estados transnacionais calcados no princípio da Solidariedade e Cooperação, uma vez que "os espaços sociais transnacionais suprimem a vinculação da sociedade a um lugar concreto (segundo a concepção nacional-estatal da sociedade)" (BECK, 2008, p. 69).

Compreender os territórios como espaços sociais transnacionais abre caminho para uma nova consciência em relação aos processos migratórios que, por sua vez, podem desencadear uma série de ações de políticas públicas entre os países, em especial nas áreas de fronteira:

Diante disso, a valoração no terreno da teoria e da práxis dos espaços transnacionais pressupõe que surgiu algo novo - uma terceira via -: interrelações de vida e atividade sociais nas quais rege 
o 'aqui e ali' ou o 'não apenas, mas também'. Sob e entre mundos separados e organizados se formam 'paisagens sociais' (Martin Albrow) que, por sua vez, enlaçam e modificam os lugares de procedência e os de destino (BECK, 2008).

Um exemplo dessa nova consciência que pode ser citado é o Equador, país que viveu uma onda de emigração nos anos noventa com a saída de cerca de 2 milhões de seus habitantes de um total de 3 milhões. Esse êxodo se deu devido à crise e perdas financeiras causadas pelo fechamento de bancos, levando os equatorianos a emigrar para os Estados Unidos e países europeus. Em entrevista4 à Fundação Memorial da América Latina durante evento que discutia a migração, no ano de 2015, o Cônsul-Geral do Equador, Luís Wladimir Vargas Anda, comentou sobre como esse movimento de emigração foi importante para a manutenção da economia do país nos anos conseguintes e para a tomada de consciência sobre as questões de mobilidade humana, tanto por parte do poder público, quanto por parte da população.

Segundo Vargas Anda, a saída e a chegada de migrantes no país levaram à necessidade de se repensar as leis, fazendo emergir a Nova Constituição de 2008 e, atualmente, o Ministério das Relações Exteriores passou a chamar-se Ministério das Relações Exteriores e Mobilidade Humana, tendo como principal objetivo garantir, tanto aos equatorianos emigrados e aos cidadãos que migraram para o Equador, a manutenção de seus direitos.

As novas leis equatorianas foram todas pensadas integrando as questões migratórias e colocando a importância do conceito de cidadania universal e o fim das fronteiras. Desta forma, foi criado o Novo Código Orgânico da Mobilidade Humana que garante aos migrantes direito à saúde, educação, moradia e direitos políticos àqueles que decidem residir permanentemente no país, e é regida pelos seguintes princípios:

\footnotetext{
${ }^{4}$ Disponível em: https://www.youtube.com/watch?v=02vBbrd7-es\&feature=youtu.be.
} 
1. Cidadania universal;

2. Livre mobilidade humana;

3. Integração regional;

4. Igualdade de direitos e deveres;

5. Proteção dos nacionais no exterior

6. Proibição de criminalização de pessoas em situação migratória;
7. Pró-pessoa;

8. Equidade;

9. Família Transnacional;

10. Bom viver

11. Eliminação Progressiva da condição de estrangeiro;

12. Reconhecimento

da

Essa mudança na visão sobre as fronteiras e sobre a mobilidade humana é de suma importância para a criação de uma legislação que busque a integração e veja os cidadãos como universais e transnacionais.

Partilha-se da ideia da eliminação das fronteiras militarizadas, das fronteiras simbólicas, como bem coloca Feldman-Bianco em entrevista para a Fundação Memorial da América Latina5, e da necessidade de campanhas educativas para combater o preconceito e discriminação contra os imigrantes. No Brasil, a noção de imigrante, em especial de grupos de grande vulnerabilidade social e econômica como latino-americanos, veiculada pela mídia, é a de invasores, delinquentes, perturbadores da ordem social e política do Brasil, além de potenciais ameaças aos empregos dos cidadãos brasileiros.

É obvio que a abertura das fronteiras exige um trabalho minucioso para a elaboração de novas leis e planejamento de políticas públicas que visem a garantia de todos os cidadãos. Entre essas políticas, é importante destacar as políticas linguísticas como uma parte desse processo, cujas ações são de suma importância para o acolhimento e integração dos migrantes e na relação com os cidadãos locais.

Desta forma, urge a necessidade de planejamento de ações que busquem integrar e acolher os migrantes falantes de outras línguas ao português, como parte do processo de empoderamento e inclusão social, pois a língua é parte primordial nesse caminho para pessoas em situação de mobilidade e que se encontram socialmente mais vulneráveis vivendo em um país linguística e culturalmente diferente. $\mathrm{O}$ acesso à língua se torna um direito no processo de mobilidade humana, um direito que possibilita o acesso a outros como a igualdade de oportunidades entre todos os cidadãos, migrantes ou não.

Essa nova realidade aponta também problemas que dizem respeito ao lugar das línguas estrangeiras no sistema educativo brasileiro, cuja regulamentação muito se afasta da noção de plurilinguísmo e cristaliza hegemonias linguísticas, como se pode comprovar com a recente Lei $n^{\circ} 13.415 / 2017$ (BRASIL, 2017b) que altera a Lei $n^{\circ}$ 11.494/2007 (BRASIL, 2007) e a Lei $n^{\circ}$ 9.394/1996 (BRASIL, 1996), esta última

\footnotetext{
${ }^{5}$ Disponível em: https://www.youtube.com/watch?v=a7VDhDoB-SQ
} 
conhecida como a Lei de Diretrizes e Bases da Educação Nacional (LDB). Dentre as alterações contidas na nova lei, cabe destacar o artigo $35 \mathrm{~A}$, inciso quarto, que regulamenta a oferta de língua estrangeira para o ensino médio:

$\S 4^{\circ}$ Os currículos de ensino médio incluirão, obrigatoriamente, o estudo da língua inglesa e poderão ofertar outras línguas estrangeiras, em caráter optativo, preferencialmente o espanhol, de acordo com a disponibilidade de oferta, locais e horários definidos pelos sistemas de ensino.

A nova legislação revoga a Lei $n^{\circ} 11.161 / 2005$, que instituía a obrigatoriedade do ensino de espanhol no currículo do ensino médio (BRASIL, 2005):

Art. 10 O ensino da língua espanhola, de oferta obrigatória pela escola e de matrícula facultativa para o aluno, será implantado, gradativamente, nos currículos plenos do ensino médio.

Oliveira e Altenhofen (2011, p. 213), ao tratarem das políticas de diversidade e da exclusão e inserção do plurilinguísmo na educação no Brasil, frisam "que uma educação de qualidade não se orienta meramente por critérios numéricos e mercadológicos e que a construção do conhecimento e do modelo de sociedade pautado em uma democracia cultural passa pela diversidade e aprendizagem de línguas", levando em consideração o contexto histórico-social em que as línguas se inserem.

Diante desse quadro de intenso fluxo migratório fica ainda mais clara a importância da elaboração de políticas linguísticas que visem resolver os desafios desse novo contexto no Brasil em busca de se ajustar às novas transformações sociais pelas quais passa o país, em especial no que se refere ao fluxo de mobilidade humana.

Hamel (1993) afirma que "a possibilidade de intervir sobre a língua está determinada pelas relações de poder vigentes entre os atores e grupos sociais"6, e essa intervenção está relacionada ao que, sob a ótica da Política Linguística, Spolsky (2005; 2009) chamou de gestão de línguas que, por sua vez, se inter-relaciona com outros dois componentes: as crenças sobre as línguas e as práticas linguísticas dos usuários das línguas em determinados contextos.

Pensar a gestão de línguas implica compreender que o mercado linguístico é determinado por diversas forças, inclusive econômicas e simbólicas, desde a perspectiva de Bourdieu (2008), que, por sua vez, vão influenciar no surgimento das crenças e sobre as práticas linguísticas de um determinado grupo.

A Política Linguística, vista aqui como uma ótica que se utiliza de outros campos

\footnotetext{
6 Tradução da autora: "la posibilidad de intervenir sobre el lenguaje está determinada por las relaciones de poder vigentes entre los actores y grupos sociales."
} 
do conhecimento como a Antropologia, História, Geografia, Sociologia, por exemplo, tem um papel primordial nesse processo de gestão e planejamento de status 7 de uma língua, podendo ser definida como "o conjunto de decisões que um grupo de poder, sobretudo um Estado (mas também uma Igreja ou outros tipos de instituições menos totalizantes) toma sobre o lugar e a forma das línguas na sociedade, e a implementação destas decisões" (OLIVEIRA, 2004, p. 38).

Sendo assim, a discussão que se traz neste artigo é a possibilidade de pensar uma política de livre mobilidade amparada por instrumentos legais, os quais teriam também como premissa o planejamento e elaboração de políticas linguísticas que levem em consideração o caráter plurilíngue e a defesa dos direitos linguísticos dos cidadãos residentes no Brasil, como forma de garantir a promoção da igualdade entre os países e proporcionar o acesso igualitário à educação, aos serviços, empregos, saúde e demais direitos assegurados pelo Estado.

\section{CONCLUSÃO}

Em síntese, o objetivo do artigo foi apresentar algumas considerações sobre a necessidade de uma mudança no modo de ver e lidar com a mobilidade humana, perpassando pelo conceito dos estados transnacionais e uma consciência de fronteiras livres como parte da nova configuração social global.

Tomou-se como exemplo o Equador e a modernização de suas leis voltadas para a mobilidade humana como forma de resolver as questões que surgiram com a massiva emigração no país na década de noventa e a chegada de migrantes, em especial colombianos e haitianos.

Tais medidas se embasam no conceito de cidadania universal expressa na Lei Orgânica de Mobilidade Humana (EQUADOR, 2017) criada após a nova Constituição do país em 2008, a qual "reconhece, a todas as pessoas, os direitos inerentes à condição humana, são sujeitos de direito como tais, independentemente de sua condição migratória" e o direito à livre mobilidade humana, respeitando desta forma o desejo de uma pessoa de mover-se livremente fora do seu país de origem, podendo residir ou não em outro país, sob o amparo da Constituição e leis internacionais.

É um grande passo reconhecer essa abertura das fronteiras e perceber que já se abre caminho para uma facilitação dos processos de mobilidade humana de forma paulatina. É um grande desafio que perpassa por questões de várias ordens, sejam políticas, econômicas e sociais, mas que revelam uma urgência diante da nova configuração mundial, se quisermos atingir parte dos objetivos para o desenvolvimento sustentável propostos pela ONU.

\footnotetext{
7 Em 1969, Kloss estabelece a diferença entre "planejamento de status" e "planejamento de corpus" de uma língua. O primeiro se relaciona à adoção de uma língua oficial, nacional ou para a educação, enquanto que o segundo diz respeito à elaboração de alfabetos, estandarização, ampliação e criação de vocabulários.
} 
Com a mobilidade, vêm sujeitos sócio historicamente construídos, sua cultura e sua língua. Língua essa que é parte da sua identidade e que não pode, não deve e nunca será substituída pela língua do novo país escolhido para construir uma nova vida. Um tratamento adequado, baseado no acolhimento e no respeito pelas culturas e línguas que estão se reunindo e começando a fazer parte do nosso cotidiano, faz-se necessário e esse é um terreno fértil para o desenvolvimento de políticas linguísticas efetivas e de grande relevância social.

\section{REFERÊNCIAS}

BECK, Ulrich. ¿Qué es la globalización? Falacias del globalismo, respuestas a la globalización. Barcelona: Ediciones Paidós Ibérica S.A., 2008.

BOURDIEU, Pierre. A economia das trocas linguísticas. 2. ed. São Paulo: Editora da Universidade de São Paulo, 2008.

BRASIL. Lei no 6.815, de 19 de agosto de 1980. Define a situação jurídica do estrangeiro no Brasil, cria o Conselho Nacional de Imigração. Diário Oficial da União, Brasília, 1980. Disponível em: < http://www.planalto.gov.br/ccivil_03/LEIS/L6815.htm> Acesso em: 15 nov. 2017.

BRASIL. Constituição da República Federativa do Brasil de 1988. Brasília: DF, Presidência da República, 1988. Disponível em < http://www.planalto.gov.br/ccivil_03/constituicao/constituicao.htm> Acesso em 20 out. 2017.

BRASIL. Lei o 9.394, de dezembro de 1996. Estabelece as diretrizes e bases para a educação nacional. Diário Oficial da União , Brasília, 1996. Disponível em: <http://www.planalto.gov.br/ccivil_03/Leis/L9394.htm> Acesso em: 05 mai. 2017.

BRASIL. Lei no 9.474, de 22 de julho de 1997. Define mecanismos para a implementação do Estatuto dos Refugiados de 1951, e determina outras providências. Diário Oficial da União, Brasília, 1997. Disponível em: <http://www.planalto.gov.br/ccivil_03/leis/19474.htm>. Acesso em: 21 nov. 2017.

BRASIL. Lei no 11.161, de 05 de agosto de 2005. Dispõe sobre o ensino da língua espanhola. Diário Oficial da União, Brasília, 2005. Disponível em: <http://www.planalto.gov.br/ccivil_03/_Ato2004-2006/2005/Lei/L11161.htm>. Acesso em: 20 nov. 2017.

BRASIL. Lei no 11.494, de 20 de junho de 2007. Regulamenta o Fundo de Manutenção e Desenvolvimento da Educação Básica e de Valorização dos Profissionais da Educação - FUNDEB... Diário Oficial da União, Brasília, 2007. < http://www.planalto.gov.br/ccivil_03/_ato2007-2010/2007/lei/l11494.htm> Acesso em 19 out. 2017.

BRASIL. Lei $\mathrm{n} \cong 13.445$, de 24 de maio de 2017. Institui a Lei de Migração. Diário Oficial da União, Brasília, 2017a. Disponível em: <http://www.planalto.gov.br/ccivil_03/_Ato2015-2018/2017/lei/L13445.htm.> Acesso em: 20 nov. 2017. 
BRASIL. Lei no 13.415 , de 16 de fevereiro de 2017. Altera as Leis nos 9.394, de 20 de dezembro de 1996, que estabelece as diretrizes e bases da educação nacional [...] Diário Oficial da União, Brasília, 2017b. Disponível em:

<http://www.planalto.gov.br/ccivil_03/_Ato2015-2018/2017/Lei/L13415.htm>. Acesso em: 20 nov. 2017.

EQUADOR, Ley orgánica de la movilidad humana, sancionada em 28 de janeiro de 2017. Disponível em

http://www.acnur.org/fileadmin/scripts/doc.php?file=fileadmin/Documentos/BDL/2017/1 0973> Acesso em: 10 dez. 2017.

FELDMAN-BIANCO, Bela. Apresentação: deslocamentos, desigualdades e violência do estado. Cienc. Cult., São Paulo , v. 67, n. 2, p. 20-24, 2015.

HAMEL, Rainer Enrique. Políticas y planificación del lenguaje: una introducción. Iztapalapa, n. 29 (Políticas del lenguaje em America Latina), p. 5-39, 1993.

OLIVEIRA, Gilvan M. de. Política Linguística, Política Historiográfica:

epistemologia e escrita da história da(s) língua(s) a propósito da língua portuguesa no Brasil Meridional (1754 - 1830). Tese (Doutorado) -Universidade Estadual de Campinas, Campinas, 2004.

OLIVEIRA, Gilvan M. de; ALTENHOFEN, Cléo V. O in vitro e o in vivo na política da diversidade lingüística do Brasil: inserção e exclusão do plurilingüismo na educação e na sociedade. In: MELLO, Heliana; ALTENHOFEN, Cléo V.; RASO, Tommaso. (Org.). Os contatos linguísticos no Brasil. Belo Horizonte: Editora UFMG, p. 187-216, 2011.

ONU. Organização das Nações Unidas. Agenda 2030 para o desenvolvimento sustentável. 2015. Disponível em: <https://nacoesunidas.org/pos2015/agenda2030/> Acesso em: 03 dez. 2018.

RICHMOND, Sociological Theories of Internacional Migration: The Case of Refugees. Current Sociology, v. 36, n. 2, 1988.

SPOLSKY, Bernard. Language Policy. In: COHEN, James et al. Procedings of the 4th International Symposium on Bilingualism. Somerville, MA: Cascadilla Press, 2005, p. 2152-2164. Disponível em: <http://www.lingref.com/isb/4/168ISB4.PDF>. Acesso em: 28 maio 2012.

SPOLSKY, Bernard.Language Management. NY: Cambridge University Press, 2009. 